\title{
Parental time restrictions and the cost of children: insights from a survey among mothers
}

\author{
Melanie Borah $^{1} \cdot$ Andreas Knabe ${ }^{1,2,3}$ (D) Kevin Pahlke ${ }^{1}$
}

Received: 4 April 2019 / Accepted: 27 September 2020/ Published online: 19 November 2020

(C) The Author(s) 2020

\begin{abstract}
An important aspect when analyzing economic inequality between households with children is time. At given monetary incomes, the material well-being of families may be very different depending on how much time parents have at their disposal. In this paper, we provide estimates of the subjectively perceived cost of children depending on the extent of parental time restrictions. Building on a study by Koulovatianos, Schröder and Schmidt (J. Bus. Econ. Stat. 27:42-51, 2009) that introduces a novel way of using subjective income evaluation data for such estimations, we conduct a refined version of the underlying survey, focusing on young women with children in Germany. Our study confirms that the perceived monetary cost of children is substantial and increases with parental nonmarket time restrictions. The experienced loss in material living standards associated with supplying time to the labor market is sizeable for families with children.
\end{abstract}

Keywords Child cost $\cdot$ Equivalence scales $\cdot$ Full-time employment $\cdot$ Subjective income evaluations

Melanie Borah

Melanie.borah@ovgu.de

Andreas Knabe

Andreas.knabe@ovgu.de

Kevin Pahlke

Pahlke.kevin@gmail.com

1 Faculty of Economics and Management, Otto von Guericke University Magdeburg, P.O. Box 4120, 39016 Magdeburg, Germany

2 CESifo, Munich, Germany

3 IWH, Halle, Germany 


\section{Introduction}

At given levels of total commodities consumption, the standard of living of households varies with their size and structure. In general, larger households need more commodities than smaller households to provide their members the same standard of living. Due to economies of scale in consumption, a household's consumption needs are generally not proportional to the number of its members. Moreover, the consumption requirements of certain household members may be systematically lower or higher than those of an average single person. Children, for instance, provide such a case. For physiological reasons (e.g. lower calorie intake), their needs may be considerably lower than those of an additional adult. Equivalence scales are an important tool capturing such differences in needs and economies of scale in household consumption. Typically, they quantify the percentage increase in a single adult's household income or expenditure necessary to leave the household's standard of living unchanged as additional members join it. Frequently, equivalence scales are restricted to considering money incomes or expenditures. While this is helpful in many applications, it neglects that material consumption requirements, in principle, can be satisfied (although not fully interchangeably) in two different ways - by purchasing marketed goods and services using money income and by producing them at home using time.

Household production as a substitute for market commodities appears to be especially relevant when one is trying to assess the cost of children. Household production can presumably satisfy a relatively large fraction of children's consumption needs at the expense of parental time (e.g., in supervisory childcare, food preparation, tutoring or leisure activities). Naturally, this will be more difficult for households whose adult members work a significant number of hours in the market and hence have less time available for household production. Time-restricted parents will have to cover more of their children's needs using marketed goods and services (e.g., by affording formal childcare services, ready-made meals, private tutors, or entertainment technologies), which increases pressure on their money income. Following this logic, the monetary cost of children, and thus their weight in the income equivalence scale, may prove sensitive to the extent of parental time restrictions. This needs to be taken into account when analyzing differences in the economic well-being of households and may have severe implications for the assessment of economic inequality between households with children.

There is a large body of literature on the monetary cost of children and their weight in income equivalence scales. Empirical approaches to their estimation either employ indirect accounts of economic well-being via observed household consumption demand and expenditure patterns or rely on direct measures of well-being using subjective survey data (for a review, see van Praag and Warnaar, 1997). The demand-based approaches suffer from problems related to the identification of utility functions that are comparable across households (see Pollak and Wales, 1979). This necessitates complex assumptions, which are often opaque and complicate the understanding of the relationship between assumptions and outcomes. Assumptions made in the literature using subjective approaches are typically more straightforward, albeit not necessarily weaker. Most importantly, they stipulate that individuals correctly assess their own household's "welfare" or "standard of living" when assigning verbal labels to actual or hypothetical levels of income or when assigning income requirements to actual or hypothetical levels of welfare (see e.g. Coulter et al., 1992, and van Praag and van der Sar, 1988). While one might be fundamentally skeptical about the interpersonal comparability and meaningfulness of subjective evaluations (see 
Bertrand and Mullainathan, 2001), various studies have shown that people answer subjective evaluation questions on income and well-being in a meaningful and consistent way (for a review, see Frey and Stutzer, 2002, pp. 406-408).

Studies that have applied the subjective method to estimate equivalence scales have generally obtained results at the lower end of the ranges known from common expert scales (e.g. the OECD scale) or those obtained by demand-based studies. Due to data limitations, most of these studies do not include parents' time input into raising their children and may thus underestimate children's relative consumption needs. One exception is a study by Koulovatianos et al. (2009), henceforth abbreviated KSS, who apply the subjective approach to estimate the monetary cost of children depending on their parents' employment status as a proxy for their time availability. They introduce a novel survey instrument that lets respondents evaluate the income requirements of hypothetical households that differ in their demographic structure as well as their nonmarket time endowment as expressed by parents' employment states. Their analysis of data collected through online surveys in Belgium and Germany suggests that there is a sizable tradeoff between money and time, in general, and that households with children require slightly larger income compensations in return for a restrictive reduction in adults' nonmarket time than childless households.

KSS's survey design allows obtaining income evaluations for arbitrary household types. It does so even if survey respondents do not belong to any such household. This doubtlessly has the advantage that one can obtain data on relative income requirements of a large number of household types even if the number of respondents is small. One might wonder, however, whether reliable answers can be obtained when respondents have only limited knowledge of the needs of households unlike their own, e.g. when asking young childless singles about the needs of married couples with children (Bradbury 1989). This is especially true for KSS' German sample, where $85.4 \%$ of the respondents do not have children and $57.9 \%$ of the respondents do not have a partner either. In fact, the majority of respondents in the German sample are male students that lack the experience of parenthood, market work and the costs associated with these two. The Belgian sample used by KSS is more balanced in terms of gender and employment, but the majority of respondents is childless as well. To address this issue, we conduct an online survey among mothers in Germany asking them to evaluate their own instead of hypothetical households' income requirements. Even though this does not give us a representative sample of the entire population, our convenience sample of mothers allows us to collect income evaluations from individuals who typically face the cost of children on a daily basis (see Pahl, 2008). By focusing on a purposefully selected convenience sample, our paper allows us to examine the robustness of KSS's findings with respect to modifications in sample selection.

Another purpose of our paper is to check the robustness of KSS's findings with respect to modifications in survey techniques. KSS ask respondents to assess income requirements of hypothetical households that differ in the number of children (and are presented in ascending order) and full-time employed adults (ordered such that households become ever more timerestricted). One could be afraid that this way of presenting the set of hypothetical households may induce a kind of focusing illusion or framing effect (Kahneman et al. 2006). Respondents might be implicitly induced to think that, as the number of children or time restrictions increase, income requirements of these households should increase as well. In this case, they might end up assigning too high values to the dimensions emphasized in the survey, i.e. children and market work. In our paper, we reduce the scope of unintended focusing by asking each respondent a single income evaluation question about one (her own) type of household. 
While it is clear that equivalence scales are supposed to represent the income differentials between households that put them on the same level of welfare or well-being, it is less clear what exactly is meant by "welfare" or "well-being". Nelson (1993) points out that, for policyrelated uses of household equivalence scales, "the critical question is what level of consumption of goods and services people are able to afford, not what level of overall happiness they may happen to attain. "(Nelson, 1993, p. 473) This concerns policy areas such as the measurement of poverty or the determination of welfare benefits for families with children. In our paper, we follow this policy-oriented perspective and analyze income differentials that keep the material standard of living, i.e. the equivalent consumption of marketed and home produced goods and services, constant. More specifically, we base our analysis on responses to the question "How much income do you think you would need in your current family situation to enjoy the same material standard of living as a single adult, who is unemployed, has no children and receives social security benefits amounting to 822 euros?"

These methodical considerations allow us to extend the study by KSS and substantiate its findings. Our results imply magnitudes and patterns of the subjectively perceived cost of children similar to those found by KSS. We follow the literature by setting the equivalence weight of a single adult (reference household) to 1, such that increases in the equivalence weights attributed to additional household members can be expressed as percentage increases relative to the needs of a single adult. Our results show, for example, that the first child of a couple in which one partner works fulltime while the other partner is not employed increases perceived financial needs by 50 to $60 \%$ of the reference household's needs, where this reference household is defined more specifically as a single, non-working, childless adult. The compensation regarded as necessary for devoting time to the labor market found in our study appears to be fairly large if there are children in the household. This suggests that the material cost of labor is mainly caused by a reduction in the time available for child-related household production activities and childcare, in particular. Moreover, we show that the subjective income evaluations reported in our survey are sensitive to the level of the respondent's actual household income. We illustrate how to correct for this "preference drift".

Our paper is structured as follows. We first review the related literature and discuss the paper by Koulovatianos et al. (2009) in detail. Section 3 provides a detailed account of the data we use, including a description of the survey design, data collection procedure, and sample characteristics. Section 4 is devoted to the empirical analysis of the survey data. It presents descriptive statistics, the econometric model, and results. Section 5 concludes.

\section{Related literature}

The determination of equivalence scales or the cost of additional household members traditionally involves an indirect account of different households' relative welfare levels. One approach lets experts assess relative needs, typically based on survey reports of actual income and expenditure. A well-known example is the (modified) OECD scale (OECD, 2005). A second approach uses objective expenditure data to estimate equivalence scales empirically. Recently, both types of scales have been extended to consider (parts of) the time cost of additional household members. Based on a review of empirical evidence regarding differences in expenditure and time use patterns of households, Folbre et al. (2017) propose an expert-type equivalence scale in extended incomes (the sum of monetary income and household production). The authors argue that economies of scale in adult-equivalent consumption and the needs 
of a child relative to an additional adult are greater in the consumption of household production than in the consumption of marketed goods and services. The equivalence parameters they suggest formalize these hypotheses but lack a precise empirical foundation. Apps and Rees (2001), Bradbury (2008) and Gardes and Starzec (2018) investigate the full consumption needs of additional household members (including domestic production and leisure) by combining information on time use with objective income and expenditure data, respectively. Apps and Rees (2001) establish that the monetary cost of children is significantly higher in households facing greater time restrictions from full-time employment. Children's full cost, however, is virtually identical across these households and is considerably larger in relation to an additional adult than the monetary cost. Bradbury (2008) and Gardes and Starzec (2018) confirm the latter result. This corresponds to various other studies that investigate solely the time cost of children and find this to be substantial (see e.g. Gustafsson and Kjulin, 1994, Bittman and Goodin, 2000, and Ekert-Jaffé and Grossbard, 2015).

An increasing body of the literature on equivalence scales centers around subjective evaluations of well-being and income. In a review of the related methods, Bradbury (1989) distinguishes four types of subjective data that can be used to approximate households' cost or welfare functions directly in order to construct the associated equivalence scales. The first type is the evaluation of one's own living standard, where respondents are asked to evaluate the level of welfare or satisfaction they experience at their current household income or, more generally, their current financial situation. The second type is the evaluation of a hypothetical living standard, where individuals have to assess the level of well-being experienced at given incomes by different hypothetically structured households. The third type represents evaluations of respondents' own income. Here, people are confronted with a description of a certain level of welfare and are asked to indicate the income they would need to enjoy that same standard of living in their current household situation. In contrast to this, the fourth type of subjective evaluations concerns hypothetical incomes, which capture a respondent's evaluation of income levels that a range of hypothetical households would require to reach a pre-specified level of welfare.

Many studies estimate equivalence scales by analyzing income differences across households of different size and structure conditional on their self-reported level of well-being, and differentiate between adults and children based on own living standards responses. Using German panel data, Schwarze (2003), van Praag and Ferrer-i-Carbonell (2004) and Biewen and Juhasz (2017) show that the equivalence weight of children is lower than the weight of additional adults (both of which also appear relatively low compared to expert scales, e.g. the OECD scale). Most studies based on data from other countries confirm this result. Notable exceptions are Rojas (2007) and Bollinger et al. (2012). Van Praag and Ferrer-i-Carbonell (2004) also employ a specification that accounts for the number of working adults. This allows them to draw conclusions about the equivalence scale depending on the household's endowment with parental nonmarket time. They find that monetary needs are greater in families with two working adults as compared to families with one working and one nonworking adult.

A number of earlier studies analyze own income responses and also find rather low equivalence weights for adults and children. By letting the same respondent evaluate a number of different welfare levels, several studies construct welfare functions of income and estimate equivalence scales on their basis (see e.g. van Praag, 1971, Kapteyn and van Praag, 1976, van Praag and van der Sar, 1988). Other studies focus on a single own income response, where respondents have to report how much income they would need to "make ends meet" (Goedhart et al., 1977). Among others, van den Bosch et al. (1993) and Garner and de Vos (1995) use this 
so-called minimum income question in the determination of equivalence scales. Similar to the latter approach, our survey relies on one single own income response for a given welfare level specified in terms of the reference household's income.

Our study builds on analyses by Koulovatianos et al. (2005, 2009), who use hypothetical income evaluations. First, Koulovatianos et al. (2005) design a questionnaire to collect hypothetical income responses, with the aim of testing the income dependence of equivalence scales. In a subsequent study, the authors adjust the survey instrument to evaluate the cost of children depending on the employment status of their parents (Koulovatianos et al., 2009). Because our paper is very closely related to it, we present the latter study's survey design and results in more detail.

Koulovatianos et al. (2009) investigate whether and by how much the monetary cost of children differs depending on a household's nonmarket time endowment. To characterize time endowments, the authors classify households by the number of fulltime employed adults within one- and two-adult households. They assume that households experience a restrictive reduction of nonmarket time when all adult members are full-time employed. A couple consisting of one full-time employed and one nonworking partner is said to face a nonrestrictive reduction of its time endowment, whereas a nonworking single or two nonworking partners are subject to no time reduction at all. These time-endowment constellations, together with differing numbers of children, define hypothetical household types whose income requirements are evaluated in the survey. Respondents indicate the net household income they think different household types need to enjoy the same standard of living as a single, childless, nonworking adult with a pre-specified net monthly reference income. More specifically, the authors ask respondents to fill in $4 \times 5$ matrices whose rows represent the number of children (from zero to three) and columns distinguish the number of adults (one or two) and their possible work status combinations (nonworking and/or working full time). The questionnaire specifies a reference income for one of these constellations (nonworking single without children), such that respondents have to fill in the remaining 19 cells. This is repeated for three different reference incomes, such that one obtains 57 observations per respondent. This survey design has the advantage that it collects information for a broad range of household types. This allows KSS to estimate equivalence scale parameters even though the number of participants to their online survey in Belgium and Germany is relatively small (149 and 164, respectively) and participants mainly come from a small number of household types.

Analyzing responses from both countries separately, KSS find equivalence scale parameters that are within the range set by other equivalence scales, but are relatively large compared to those found by earlier studies using the subjective approach. Equivalence weights tend to fall with reference income, which suggests that there are more economies of scale when living standards are higher. Most importantly, the results indicate that the monetary cost of children is significantly higher in fully time-restricted than in other households, whereas a non-restrictive reduction in nonmarket household time does not affect the income requirements associated with a child. The results imply that the tradeoff between money and time is significantly higher in households with children when all adults are working full-time. At the same time, the results suggest that there is a strong tradeoff between money and time even if there are no children in the household. The disutility of labor thus appears to be substantial. 


\section{Data}

\subsection{The questionnaire}

We analyze responses to an online questionnaire that we created using the software package SoSci. We provide an English version of the entire (originally German) questionnaire in the online appendix. The maximum number of questions a respondent had to answer was 17 . The majority of questions concerned the socio-economic characteristics of the respondent, his/her children and, if applicable, his/her partner. Supplemented by a single income evaluation question, the generated dataset provides a suitable basis for the analysis of additional household members' financial needs.

Among the inquired personal characteristics are the respondent's nationality, region of residence (German federal state), gender, age, highest educational degree and employment status. Gender information is used to restrict the sample to women, while the other variables serve as covariates in our main empirical analysis. Of special importance is the employment status, which subsumes if the respondent is currently working, the kind of employment or nonemployment, as well as weekly hours of work, if applicable. Furthermore, we asked individuals to state if they were single or in a relationship with a partner living either in the same or in a separate household. We also requested them to indicate if there were any other adult household members except for them, their partners or, possibly, their children. To construct a measure of the time restrictedness of the respondent's household, we had to assess the partner's employment status, if present. This involved the exact same questions as those concerning the respondent's own employment. In order to investigate the differential monetary needs of children given the differences in their parents' non-market time endowment, we also asked respondents to state the number and age of children living in their households.

In the second-last question of the survey, we enquired respondents to specify their household's actual net monthly income. In an attempt to receive measures as accurate as possible, we provided a detailed list of income components that they should include in the respective answer. Finally, we assessed our dependent variable via the following question regarding own income requirements:

"How much income do you think you would need in your current family situation to enjoy the same material standard of living as a single adult, who is unemployed, has no children and receives social security benefits amounting to 822 euros?"1

822 euros was the average amount of monthly welfare benefits to households provided by the German welfare system (Arbeitslosengeld II) in 2012 (Bundesagentur für Arbeit, 2013). Although it is more than $60 \%$ higher than the lowest reference income used by $\mathrm{KSS}^{2}{ }^{2}$ it reflects a relatively low standard of living in Germany. To remind respondents of the dimensions along which they differ from the reference household, we presented a table to them, contrasting their own to the hypothetical household's characteristics. It summarized the respondents' earlier statements regarding their household's number of adults, their

\footnotetext{
${ }^{1}$ In German, the question reads: "Was benötigt Ihrer Meinung nach ein Haushalt in Ihrer aktuellen Familiensituation, um den gleichen materiellen Lebensstandard zu erreichen wie ein alleinstehender Erwachsener, der nicht arbeitet, keine Kinder hat und eine Grundsicherung von 822 Euro bezieht?"

${ }^{2}$ We set all our results in relation to estimates by KSS that rely on the assumption of a reference income of 500 euros.
} 
employment, and the number of children in comparison to the details mentioned in the above question. Table 1 represents an illustrative example.

Below the table, respondents had to fill in the net income that they considered equivalent to the reference income, in the sense of being necessary to enjoy the same material standard of living, given the differences in their household's characteristics (as indicated by the "???" cell). A response to this question completed the survey.

\subsection{Data Collection}

Bradbury (1989) argues that people are better able to evaluate their own household's income requirements than those of a hypothetical, differently composed household. When the research focus is on the cost of children, it thus seems desirable to ask parents about their income evaluations. Furthermore, it may be beneficial to enquire individuals that are concerned with the household's child-related expenditures primarily. These are typically mothers. ${ }^{3}$ Therefore, we have made an effort to let as many mothers as possible answer our questionnaire. Although our research design still requires respondents to evaluate implicitly the hypothetical reference household's standard of living when assessing their own income requirements, we think that most mothers will likely be able to compare themselves to this household type. This is because many of them will have experienced episodes of being single and childless, and perhaps even unemployed, in the past. The income response's speculative component is therefore considerably lower than in KSS's assessment of income requirements in household arrangements completely unknown to the respondent.

We recruited a convenience sample of respondents via the social networking site Facebook. ${ }^{4}$ A multitude of Facebook groups address parents specifically and thus allow an easy identification of people in our target group. Therefore, we could post an appeal to participate in our survey to 116 groups and two large communities ${ }^{5}$ directly related to parenthood or the exchange of child-specific goods and advice. Sometimes this required the approval by a group administrator whom we had to contact first. Because we designed our survey to study the financial needs of German households, we placed our call in German groups only. At the time of survey, the number of members within the groups ranged from 59 to 10,786 , whereas the communities had as many as 277,339 and 182,248 subscribers. Altogether, this resulted in a total number of 736,922 potential participants, in theory. Of course, this number is extremely optimistic because many members or subscribers probably

\footnotetext{
${ }^{3}$ For empirical evidence in support of this view, see Pahl (2008).

${ }^{4}$ Facebook members are not necessarily representative of the entire population. Recruiting respondents from this social network might thus cause a sample selection bias. To alleviate this problem, we compare our sample to nationally representative data from the German Socio-Economic Panel (SOEP). We calculate sample weights to approximate the distribution of household income, the number of children, presence of a partner and years of education of mothers in the same age group (as defined by our sample's age quintiles) in the SOEP. The regression results of this robustness test are similar to those of the unweighted sample and support our main results. Detailed results are available upon request. A sample selection bias we cannot rule out may exist, however, if less time-stressed mothers (within each employment arrangement) are more likely to be part of Facebook and respond to our survey. The cost of children accruing to employed parents would then be underestimated.

${ }^{5}$ Groups are designed for relatively small numbers of people to communicate on subjects of common interest and are either public or private, as chosen by the initiator. Community pages, on the other hand, are official profiles of public figures, businesses and organizations that are publicly available to all internet users.
} 
Table 1 Summary tool - example

Your own household

\begin{tabular}{lll}
\hline Relationship status: & In a partnership & Single \\
Employment status: & Both working & Not working \\
Number of children: & 3 children & No children \\
Income: & $? ? ?$ & $€ 822$ \\
\hline
\end{tabular}

did not access Facebook at all, or did not receive notifications from the groups or communities during the survey period.

We conducted the survey in February 2017. A personal message explaining the purpose of our study and a link to the survey were posted to each group between February 5 and February 11, 2017. Facebook gave all group members the option to comment on our entry. This option was valuable to us for three reasons. Firstly, it allowed for the timely interaction with potential respondents and the clearance of their questions. Secondly, each comment led to a refreshment of the newsworthiness of the entry, leading it to appear at the top of the page repeatedly. This may have enhanced the visibility of our request and thus may have increased the response rate. Thirdly, having people recommend the survey to friends with the help of a reference in the comment section may have helped to achieve the same result. Seven to ten days after our entry's first appearance, we posted a reminder also indicating the date at which our survey would expire. The online survey tool was deactivated on February 28, 2017, thus ending the process of data collection.

We received 1062 responses. 935 respondents answered the survey completely.

\subsection{Sample characteristics}

Of the 935 completed questionnaires, only 59 came from male respondents. We dropped these responses because they did not match our target group of mothers. Because of ambiguities in the income evaluation of individuals that live separately from their partners, we also excluded 58 women who reported to have a partner not living within the same household. With the data collection organized according to the narrow definition of our target group, the number of childless individuals that had participated in our survey was very low. Not considering them led to a loss of only nine observations. There are no households with other adult members (except for the partner) in our sample, because indication of the same led to the immediate termination of the survey. Hence, we have ensured that apartments shared by extended families or unrelated adults do not affect our estimated equivalence scales. To approximate the needs of dependent children, we exclude households from the analysis that consist of at least one child above the age of 17 . This concerns 16 observations and leaves us with information about 793 mothers and their households.

Unfortunately, from some of these mothers we have received implausible responses to the income evaluation question. Although previous answers clearly suggested that their households consisted of more people than the reference household, they declared to require less income than a childless single to enjoy the same material standard of living. This concerns 46 responses. We cannot be sure if these statements are the result of a misunderstanding, a normative judgement about the adequacy of social security benefits in general, or the inclusion of non-pecuniary welfare effects of additional household members. We also cannot be sure whether this concerns only those 46 households or whether these issues also arise for some of 
the other households. In any case, stated income requirements of less than $€ 822$ certainly do not correspond to our understanding of what this variable should capture. Hence, we have decided to exclude the 46 critical observations from our empirical analysis. ${ }^{6}$ Our final sample thus comprises 747 observations.

We provide sample statistics for some of the enquired control variables in Table 2.

A comparison of the sample characteristics with the individual characteristics of respondents in the German sample of KSS shows that our survey responses more strongly represent working families with children. While the large majority (more than $85 \%$ ) of respondents in the sample of KSS reported to have no children, our sample allows us to analyze the income responses of people who actually face the cost of children in everyday life. This allows us to test whether the KSS results can be generalized and apply also to families with children. Furthermore, our number of independent observations is considerably larger than in the KSS study, which considers 19 clearly interrelated hypothetical incomes stated by each of the 164 respondents.

Overall, we see that the vast majority of our sample of mothers is German, lives with a partner, and is between 20 and 40 years old. More than $89 \%$ of the respondents have either one child or two children. Many women in our sample have completed a vocational training. Despite motherhood, a large fraction of our sample is in employment. Yet, this percentage is small in comparison to the employment share of the respondents' partners. Differences also exist in the working time of mothers and their partners. On average, mothers spend $29 \mathrm{~h}$ per week in paid employment while their partner works about $42 \mathrm{~h}$ per week. The mean net household income in our sample is about $€ 2661$. Only a small fraction of households $(<5 \%)$ reports to have an actual income below the reference level of $€ 822$.

\section{Empirical analysis}

\subsection{Descriptive statistics}

In the empirical analysis of this paper, the variable of primary interest is the ratio of the income that respondents need to reach the pre-specified material standard of living and the reference income. This quotient represents the equivalence weight that the respondent assigns to her household in order to achieve the same level of material well-being as an unemployed single adult with an income of $€ 822$. Following KSS, we call this variable the equivalent-income ratio. Table 3 presents its means and standard deviations for households differentiated by the number of adults and children as well as by the incidence of full-time employment (W), which is defined as being employed and working for $35 \mathrm{~h}$ per week or more. Our focus on full-time employment is motivated by its direct comparability to KSS as well as preliminary analyses that showed lower compensations for children in time-restricted households when this restrictedness was defined in terms of part-time employment. ${ }^{7}$ Table 3 also reports the number

\footnotetext{
${ }^{6}$ A robustness test confirmed that retaining those 46 observations in our sample results in only small changes in the estimated coefficients. Our results remain qualitatively unchanged.

${ }^{7}$ We conducted our analyses applying different definitions of being time-restricted, i.e. we considered an adult as restricted by "working" when he/she reported to work more than $20 \mathrm{~h}$ per week or any positive number of hours. Weaker definitions of time restrictions do not affect the estimated coefficients for adults and children considerably but lead to lower or even insignificant compensations for children in time-restricted households. The results are available upon request.
} 
Table 2 Sample characteristics

\begin{tabular}{|c|c|c|c|c|c|}
\hline & $\mathrm{N}$ & $\%$ & & $\mathrm{~N}$ & $\%$ \\
\hline Total & \multirow{2}{*}{\multicolumn{2}{|c|}{747}} & & & \\
\hline Nationality & & & \multicolumn{3}{|l|}{ Own Employment } \\
\hline German & 728 & 97.5 & $\overline{Y e s}$ & 463 & 62.0 \\
\hline Others & 19 & 2.5 & No & 284 & 38.0 \\
\hline Partner & & & Employment of the Partner & \multicolumn{2}{|c|}{$(N=654)$} \\
\hline Yes & 654 & 87.6 & Yes & 617 & 94.3 \\
\hline No & 93 & 12.4 & No & 37 & 5.7 \\
\hline Children & & & Own Working Time & \multicolumn{2}{|c|}{$(N=463)$} \\
\hline One & 402 & 53.8 & $<=20$ & 140 & 30.2 \\
\hline Two & 264 & 35.3 & $>20$ and $<35$ & 160 & 34.6 \\
\hline Three & 66 & 8.8 & $>=35$ & 163 & 35.2 \\
\hline More than Three & 15 & 2.0 & & & \\
\hline Age & \multicolumn{2}{|c|}{ Mean: 31.00} & Partner's Working Time & \multicolumn{2}{|c|}{$(N=617)$} \\
\hline$\overline{<20}$ & 6 & 0.8 & $<=20$ & 9 & 1.5 \\
\hline $20-40$ & 710 & 95.0 & $>20$ and $<35$ & 12 & 1.9 \\
\hline$>40$ & 31 & 4.1 & $>=35$ & 596 & 96.6 \\
\hline Highest Degree & & & Net household income & \multicolumn{2}{|c|}{ Mean: 2661.19} \\
\hline No degree & 3 & 0.4 & $<822$ & 36 & 4.8 \\
\hline Secondary School & 139 & 18.6 & $822-1624$ & 150 & 20.1 \\
\hline Abitur & 48 & 6.4 & $1625-2374$ & 150 & 20.1 \\
\hline University Degree & 153 & 20.5 & $2375-3124$ & 173 & 23.2 \\
\hline Vocational Training & 348 & 46.6 & $>=3125$ & 238 & 31.9 \\
\hline Others & 56 & 7.5 & & & \\
\hline
\end{tabular}

of observations for each of the family types, thus informing about the distribution of household characteristics within our sample.

We observe the equivalent-income ratio for single mothers and couples with up to four children. Because there is only a small number of households having four children, we do not include them in the presentation of Table 3. Thus, we distinguish households according to the number of children in three rows. The sample statistics in the first two columns refer to single

Table 3 Mean equivalent-income ratio by household type

\begin{tabular}{|c|c|c|c|c|c|c|}
\hline \multirow[b]{2}{*}{ Number of Children } & \multicolumn{3}{|l|}{ Single } & \multicolumn{3}{|c|}{ Couple } \\
\hline & $\mathrm{N}$ & $\mathrm{W}$ & $\mathrm{NN}$ & & WN & WW \\
\hline 1 & $\begin{array}{l}\mathbf{1 . 6 9} \\
(0.44) \\
41 \\
* *\end{array}$ & $\begin{array}{l}\mathbf{1 . 9 2} \\
(0.46) \\
12 \\
*\end{array}$ & $\begin{array}{l}\mathbf{2 . 1 3} \\
(0.72) \\
21 \\
* *\end{array}$ & $* * *$ & $\begin{array}{l}\mathbf{2 . 6 8} \\
(1.11) \\
234 \\
* * *\end{array}$ & $\begin{array}{l}\mathbf{2 . 6 0} \\
(1.53) \\
94 \\
* *\end{array}$ \\
\hline 2 & $\begin{array}{l}\mathbf{1 . 9 6} \\
(0.56) \\
24\end{array}$ & $\begin{array}{l}\mathbf{2 . 3 5} \\
(0.28) \\
3\end{array}$ & $\begin{array}{l}\mathbf{2 . 7 1} \\
(0.84) \\
20\end{array}$ & & $\begin{array}{l}\mathbf{3 . 0 1} \\
(1.18) \\
188 \\
* *\end{array}$ & $\begin{array}{l}\mathbf{3 . 1 7} \\
(1.21) \\
29\end{array}$ \\
\hline 3 & $\begin{array}{l}\mathbf{2 . 0 7} \\
(0.52) \\
9\end{array}$ & $\begin{array}{l}\mathbf{3 . 5 3} \\
(0.69) \\
2\end{array}$ & $\begin{array}{l}\mathbf{2 . 5 9} \\
(0.90) \\
4\end{array}$ & $*$ & $\begin{array}{l}\mathbf{3 . 6 3} \\
(1.53) \\
40\end{array}$ & $\begin{array}{l}\mathbf{3 . 8 1} \\
(1.68) \\
11\end{array}$ \\
\hline
\end{tabular}

$N$ stands for a single, non-full-time employed, $W$ for a single full-time employed mother. NN refers to a couple with no, WN to a couple with one and WW to a couple with two full-time employed parents

Each cell consists of the mean equivalent-income ratio (in bold) in relation to a single, childless, nonworking adult, the standard deviation (in parentheses) and the number of observations. Stars between two cells indicate that the difference between their means is statistically significant with $* p<0.1, * * p<0.05$, *** $p<0.01$ 
mothers without $(\mathrm{N})$ and with full-time employment (W). From the number of observations reported in the third line of each cell, we know that full-time employment among single mothers in our sample is quite rare, especially when there is more than one child. The first line of each cell reports the mean equivalent-income ratio generated from responses of women in the respective households. With the reference household's income normalized to one, we can immediately derive the percentage increase in income needed for different households to enjoy the same material standard of living. From the top left cell, for instance, we can conclude that non-working single mothers with one child report that they need, on average, 69\% more income than a non-working single without children to enjoy the same material standard of living. Single full-time employed mothers require an even greater average monetary compensation of $92 \%$ for the first child and their time restriction or material cost of labor. For any number of children, the positive difference between the income requirements of working and non-working single mothers is not statistically significant, though. By comparing means vertically, we can investigate the income increase needed for additional children. For single mothers without full-time employment, the additional cost of a second or third child seems to be much lower than that of the first. Small numbers of observations for some of the single-mother household types restrict our ability to draw reliable conclusions, though.

For couples, we distinguish the degree of time restrictedness by considering three possible combinations of adults' employment states. Column NN refers to two adults who both are not full-time employed. The combination WN represents what KSS call the 'traditional household', in which one adult works full-time whereas the other one does not. While the great majority of households in this group (i.e. 97.5\%) consists of a full-time employed husband and a part-time employed or nonworking wife, we also observe 12 households with the opposite arrangement. $^{8}$ The last column studies fully time-restricted households, whose adult members both are in full-time employment. The distribution of the number of observations clearly shows that the 'traditional household' is the most common household arrangement in our sample. Again, mean equivalent-income ratios provide first evidence regarding the cost of additional household members under different time constraints. As is the case for singlemother households, the confidence intervals of most estimates are quite wide, however. From the descriptive statistics and simple mean comparisons, it is thus very difficult to draw unambiguous conclusions regarding the cost of children in differently time-constrained households. A multivariate regression analysis will prove more helpful in this regard.

\subsection{Econometric model}

Because one aim of this paper is to find out whether the results by Koulovatianos et al. (2009) are reproducible using a different sample and survey design, our empirical analysis closely follows the regression model of that study. KSS estimate an equivalence scale proposed by Cutler and Katz (1992). We do the same and regress the stated equivalent-income ratio (EIR) on the accordingly defined household's equivalence weight along with other personal and household characteristics that might affect responses to the hypothetical income question. This leads us to our Baseline Specification:

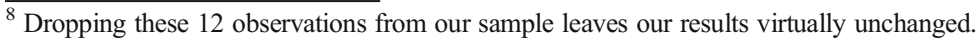




$$
E I R_{i}=\left(n_{A i}+\alpha n_{C i}\right)^{\theta}+X_{i}^{\prime} \mathrm{b}+e_{i}
$$

(Baseline)

The first term on the right-hand side represents the equivalence scale, where $n_{A}$ is the number of adults in the household and $n_{C}$ is the number of children. $\alpha$ is the weight that a child receives in relation to an additional adult and the parameter $\theta$ captures economies of scale in adult equivalents. $e_{i}$ is the error term and $X_{i}$ is a vector of personal and household characteristics that may also have an impact on the own income response. To facilitate comparisons to KSS, we include the respondent's age, her education as measured by the highest degree attained, a dummy for being a German national as well as the state of residence in all our main regressions. One could argue, however, that controlling for these factors contradicts our policy-oriented approach because there is a natural link between some of these variables and the number of children or employment constellations (e.g. age) that should not be excluded from compensations to be paid. To address this concern, we provide results based on estimations not including any of these personal or household characteristics in the online appendix (Table A1 and A2). To test whether actual household incomes are related to own income responses, we do consider the respondent's monthly net household income in parts of the main and unconditioned regressions. ${ }^{9}$

We obtain a model that is very similar to KSS by extending the definition of the equivalence scale by the number of working adults. This produces the following Specification 1:

$$
E I R_{i}=\left(n_{A i}+\alpha n_{C i}+\beta n_{W i}\right)^{\theta}+X_{i}^{\prime} \mathrm{b}+e_{i}
$$

$n_{W i}$ reflects the number of working adults in the household of respondent $i$ and the associated coefficient $\beta$ quantifies the compensation for an adult's full-time employment relative to the cost of an additional non-working adult.

Specification 2 provides a more detailed account of the differential cost of children in relation to the employment status of their parents. It does so by interacting the number of children with dummies indicating the degree of the household's time restrictiveness:

$$
E I R_{i}=\left(n_{A i}+\alpha n_{C i}+\beta n_{W i}+\gamma n_{C i} D_{W N i}+\delta n_{C i} D_{F i}\right)^{\theta}+X_{i}^{\prime} \mathrm{b}+e_{i}
$$

$D_{W N i}$ is equal to one if household $i$ is a 'traditional household' with only one of two partners being full-time employed and zero otherwise. $D_{F i}$ refers to households that are fully timerestricted and is equal to one if either a single or both adults in a couple are in full-time employment. The assessment of a child's relative weight in those households must consider all the related coefficients. While it equals $\alpha$ in a household with no full-time employed adults, it is the sum of $\alpha$ and $\gamma$ in a traditional and the sum of $\alpha$ and $\delta$ in a fully time-constrained household.

One question we seek to answer is whether our results are robust to the functional form that we impose on the equivalence scale. By assuming a Cutler and Katz parametrization, our regression model is clearly nonlinear. Therefore, we estimate equations (Baseline) to (2) by nonlinear least squares. It is easy to transform these into analogous linear equations if one is willing to assign fixed equivalence weight increments to specific household members, as in the

\footnotetext{
${ }^{9}$ Equivalence weight increments estimated from regressions controlling for actual household income are similar across models including and excluding further household and personal characteristics. The inclusion of household income, however, results in considerably greater changes in these increments when disregarding further controls as opposed to when they had been included.
} 
commonly applied OECD scale (see OECD, 2005). We do this and estimate the linear alternatives to the three previous specifications:

$$
\begin{gathered}
\operatorname{EIR}_{i}=1+\tau\left(n_{A i}-1\right)+\alpha n_{C i}+X_{i}^{\prime} \mathrm{b}+e_{i} \\
E I R_{i}=1+\tau\left(n_{A i}-1\right)+\alpha n_{C i}+\beta n_{W i}+X_{i}^{\prime} \mathrm{b}+e_{i} \\
E I R_{i}=1+\tau\left(n_{A i}-1\right)+\alpha n_{C i}+\beta n_{W i}+\gamma n_{C i} D_{W N i}+\delta n_{C i} D_{F i}+X_{i}^{\prime} \mathrm{b}+e_{i}
\end{gathered}
$$

The advantage of estimating these linear alternatives is that they yield the equivalence weight change associated with additional household members immediately. Thus, we can evaluate the relative cost of a child independently of the total number of family members.

A second issue we want to address is the role that a respondent's actual income plays in determining her income response and hence the equivalent-income ratio assigned to her household. We would expect respondents to indicate greater income requirements the higher their actual household incomes and thus current consumption habits are. To control for this 'preference drift' (van Praag, 1971, Kapteyn and van Praag, 1976), we include the ratio of actual to reference income in supplementary regressions of all linear and nonlinear specifications. As actual household income is positively correlated with the number of adults, full-time employed adults and children (with a correlation coefficient of $0.329,0.308$ and 0.159 , respectively), omission of this variable would lead to an overestimation of the unadjusted equivalence parameters for (working) adults and children. Our method, which is based on own income responses, is much more prone to such bias than KSS' method, which is based on hypothetical income responses. Even though respondents' actual incomes are likely to affect the absolute levels of income they think are needed by different types of hypothetical households, there is no obvious reason why actual income should affect the relative differences between them (Bradbury, 1989). Indeed, the similarity of KSS' estimates before and after the inclusion of respondents' actual incomes indicates that no such bias exists in their approach. Thus, we think a fair comparison between our study and theirs is one where we control for the preference drift.

If actual incomes affect own income responses significantly, it will be necessary to correct the estimated equivalence weights (Bradbury, 1989). This is because a respondent, whose actual income is higher than that needed to attain the reference household's material standard of living, would indicate lower income requirements once she received the income that she had previously deemed necessary. To be able to make consistent comparisons of income responses across differently composed households, one therefore has to calculate the income requirement for a household whose actual income corresponds to this income requirement. Here, we use the same method as often applied in studies of the minimum income question or income functions (see e.g., van Praag and van der Sar, 1988). It implicitly imputes current household incomes that would lead respondents to state these as their required incomes. In the linear version of our Baseline Specification, for instance, the inclusion of the actual-income ratio $\left(Y_{i} / 822\right)$ as a regressor yields the following equation:

$$
E I R_{i}=1+\tau\left(n_{A i}-1\right)+\alpha n_{C i}+\lambda\left(Y_{i} / 822\right)+X_{i}^{\prime} \mathrm{b}+e_{i}
$$


Under the provision that current incomes must be equal to required incomes, $E I R_{i}=\left(Y_{i} / 822\right)$, we can express the equivalent income ratio by

$$
E I R_{i}=\frac{1}{1-\lambda}+\frac{\tau}{1-\lambda}\left(n_{A i}-1\right)+\frac{\alpha}{1-\lambda} n_{C i}+X_{i}^{\prime} \frac{\mathrm{b}}{1-\lambda}+\frac{e_{i}}{1-\lambda},
$$

where $\lambda$ is the coefficient on the actual-income ratio, which usually ranges between zero and one. To correct for the preference drift, we thus only need to multiply the equivalence weight increment for the respective family member by the factor $1 /(1-\lambda)$. This also applies to the nonlinear model, where we first have to calculate the equivalence weight increments from the estimated parameters before we can apply the correction factor.

\subsection{Regression results}

We now turn to the presentation of the results obtained from our novel dataset. As these are directly comparable to the results by KSS, we first focus on the parameter estimates obtained from the non-linear model. After that, we will consider the linear model assuming fixed equivalence weight increments. The estimated coefficients allow us to calculate equivalence weight increments associated with specific household members that are comparable across models and can be adjusted for a potential preference drift caused by own household income. This will help us evaluate the sensitivity of our findings with respect to the chosen specification as well as own income effects.

\subsubsection{Nonlinear model}

The top panel of Table 4 summarizes the parameters obtained from estimating our three main specifications in the nonlinear framework (the (Baseline) and eqs. (1) and (2)). The first column of each specification presents the coefficients estimated when ignoring the respondent's actual income, while we account for it in the second column. Except for the baseline specification, which was not considered in the KSS study, the third column to each specification lists parameter estimates by KSS that are based on their German subsample taking a reference income of $€ 500$ as given. The bottom panel of Table 4 reports the equivalence weight increments associated with a selection of household members to illustrate the implications of the estimated parameters. To allow a fair comparison between adults and children, all of the numbers refer to a third person joining the household.

Consider first the regressions that do not include the respondent's actual household income. In the baseline specification, we estimate the most classical form of the Cutler-Katz scale not accounting for time restrictions of households. We find that the necessary income increase associated with a child is about $56 \%$ of that of an additional adult (parameter $\alpha$ ). The economies of scale parameter $\theta$ is found to be very close to one, implying relatively low economies of scale in the number of adult equivalents. As a result, the equivalence weight increment of an additional adult amounts to $87 \%$ and that of a child to $49 \%$, irrespective of the employment status of the adults.

Specification 1 introduces the number of full-time employed adults into the analysis. We find the relative weight of a child to be higher and the scale parameter $\theta$ to be lower than in the baseline specification. Our estimate of the parameter $\beta$ indicates a small and statistically insignificant income increment required to compensate full-time employment. Combining relative weights and the scale parameters, one finds the equivalence weights reported in the 


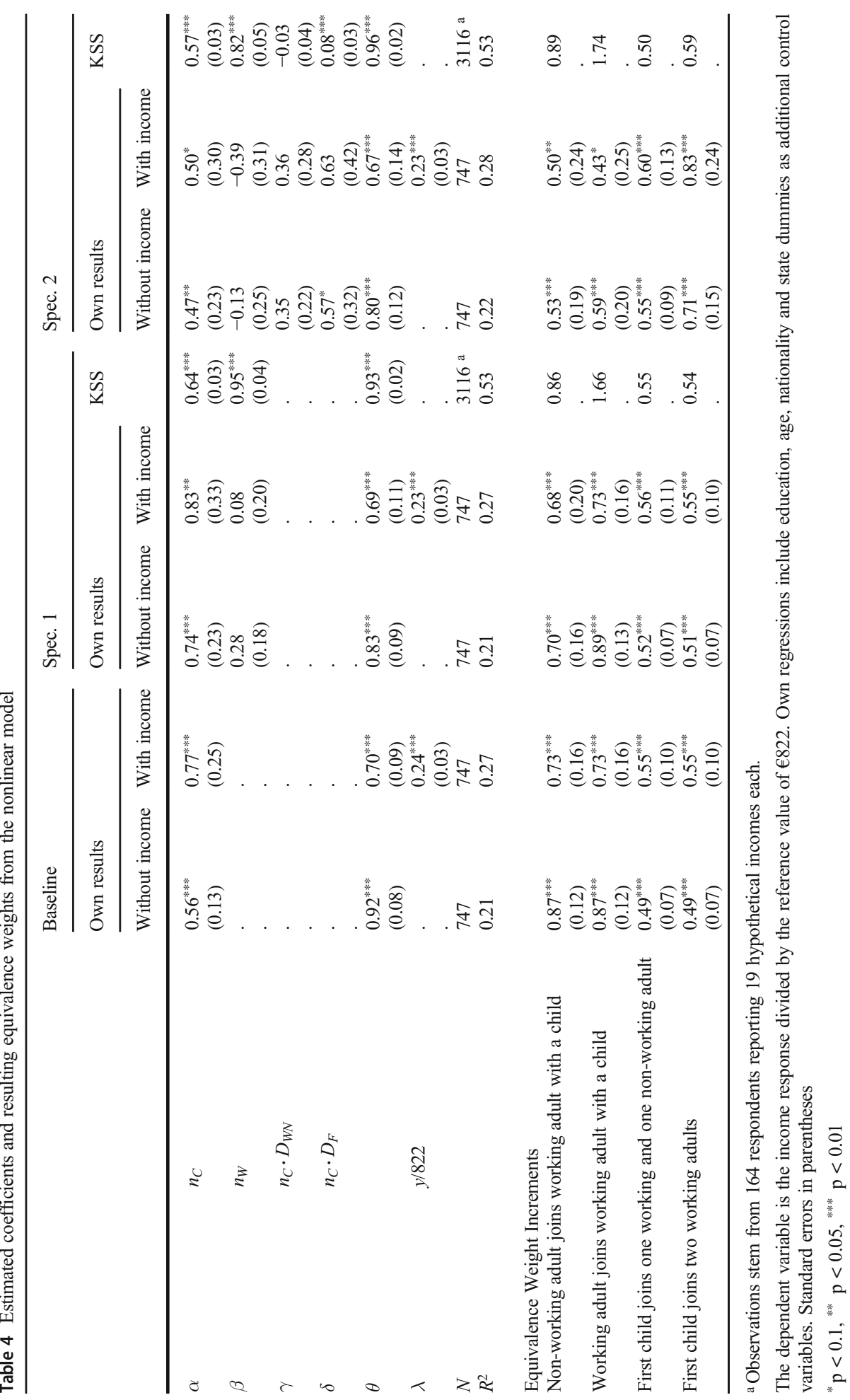


bottom part of Table 4. These are almost equal to the weights suggested by the 'old OECD scale', assigning an incremental weight of $70 \%$ to an additional adult and $50 \%$ to a child. The equivalence weight increase associated with a child is virtually identical regardless of whether it joins a household with two working or one working and one non-working adult. An additional working adult requires a 19-percentage point higher income increment than an additional non-working adult, but this difference is statistically insignificant.

Specification 2 indicates that the material cost of time restrictions becomes sizeable as the number of children increases. The inclusion of the two associated interaction effects in Specification 2 causes the relative weight of a child in a non-restricted household to fall to about $47 \%$. Parameter $\gamma$ indicates a large (although statistically insignificant) increase in this weight when there is one working adult among the two parents. In a fully time-restricted household, consisting of either one full-time-employed single or two full-time-employed partners, a child's relative weight increases by almost 60 percentage points (as shown by $\delta$ ). The differential cost of children becomes visible more clearly in the equivalence weight increments of children joining an existing household that are reported in the bottom panel of Table 4. While a child to a 'traditional' household requires nearly the same income increment as an additional adult forming the same kind of household (about 55\%), its weight is about $70 \%$ when joining a fully time-constrained household. Shifting from non-employment to employment thus increases the income requirements of households with children considerably. Contrary to that, we do not find evidence that an adult's full-time employment causes material cost when there are no children in the household $(\beta)$. If anything, the effect appears to be negative, suggesting that childless people derive a positive material benefit from working.

We have argued before that all results reported until now might suffer from a bias induced by preference drift. A closer look at the second column of each specification reveals that our results are indeed quite sensitive to the inclusion of actual household incomes. In the following, we will briefly discuss the associated changes. The results presented in the top panel of Table 4 are the unadjusted coefficients obtained immediately from the regressions. Only the equivalence weight increments in the bottom panel encompass the correction for the preference drift in the parameter estimates that we introduced in the previous subsection. They provide the most suitable basis for making comparisons with the results by KSS.

Focusing first on the top panel results, we find that in all three specifications the ratio of actual to reference income has a strong positive effect on the equivalent income ratio. This confirms the preference-drift hypothesis. As the relation between actual household income and the number of adults is positive, the parameter $\theta$, which captures economies of scale in adult equivalents, declines compared to when actual income is not included in the regression. In all three specifications, it ends up to be close to 0.7 . At the same time, the relative weight of children goes up to partially counteract this influence. When we control for the number of working adults, as we do in specifications 1 and 2, the negative effect of considering actual incomes on the employed adult's relative weight is visible in $\beta$ as well.

These findings have an immediate bearing on the equivalence weights reported underneath. Even after adjusting the parameters for the preference drift in income responses, the additional adult's weight increments remain below the values reported in the first column of each specification, whereas those of the first child generally increase. Comparing the last two specifications' results to KSS, only one remarkable difference appears. This concerns the weight of an additional full-time employed adult. In the study by KSS, full-time work involves a near doubling of the perceived income requirements of an additional adult. Our Specification 1 , on the other hand, indicates a very small and insignificant supplementary income 
compensation for full-time employment. Specification 2 even points towards an insignificantly negative compensation. As a result, the equivalence weight increments reported in the second row of the bottom panel are substantially lower than in KSS' study. In fact, these are the only equivalence weight estimates whose $95 \%$ confidence intervals do not include KSS' point estimates. Even though the equivalence weight increment of an additional non-full-time employed adult also appears to be much smaller than in KSS' study, we do not find robust evidence for significantly lower weights for additional adults in general due to the statistical imprecision of our estimates. Estimates regarding the cost of children are remarkably similar across both studies. While the first child's equivalence weight increment is nearly identical across studies in Specification 1, Specification 2 produces the same qualitative finding regarding the cost of children as KSS. It shows that the cost of a child to a fully timeconstrained household is larger than to non- or only partially time-restricted households. Unfortunately, this difference is not statistically significant when accounting for preference drift (as visible from our top-panel estimate of $\delta$ ). The magnitudes of these estimates, however, confirm KSS' main result. Since we find that the material cost of labor market work substantially increases in the presence and number of children, while we do not obtain evidence for a material cost of labor for childless individuals, our results indicate that additional income requirements arise entirely because of time restrictions in childcare. ${ }^{10}$

The differences between our findings and those of KSS could be the result of respondents considering material instead of a more general concept of living standards. Our survey question differs from that of KSS, whose instruction reads as follows: "Please, fill in the cells putting the after-tax/transfer family income that you believe brings the households that differ with respect to the numbers of children, adults, and working adults, to the same living standard as the one of the nonworking single childless adult". While we inquire explicitly about material living standards, their more general reference to living standards could be interpreted by respondents as something closer to total utility than to purely material living standards, thus also including the benefits of leisure. Therefore, when holding the general standard of living constant, greater monetary needs of working adults may stem from three different sources. First, there may be expenditures directly related to being employed (costs of commuting, work equipment etc.). Second, labor market work decreases the time available for household production activities, which can be substituted for by the purchase of market goods and services (e.g. eating out instead of cooking at home or affording external childcare). Third, individuals may seek monetary compensation for their loss in leisure, which would allow them to substitute leisure by material consumption. While the first two kinds of compensations are supposed to hold the household's material standard of living constant, the third one increases it counteracting the loss of leisure time to keep utility unchanged.

The comparison of our results to KSS' suggests that households with no or just one child do not require additional income to be compensated for the loss in their material consumption of goods and services when devoting more time to market work, but need a significant increase in income to compensate the loss in their general living standard. If the above reasoning applies, this may be indicative of time restrictions affecting these households mainly through the pure loss in leisure and not via the reduction in time available for household production.

\footnotetext{
${ }^{10}$ We have also run regressions differentiating between children of ages zero to five and children of ages six to seventeen. The point estimates suggest that older children are associated with lower costs than younger kids. The differences are not statistically significant, though. Detailed results are available upon request.
} 


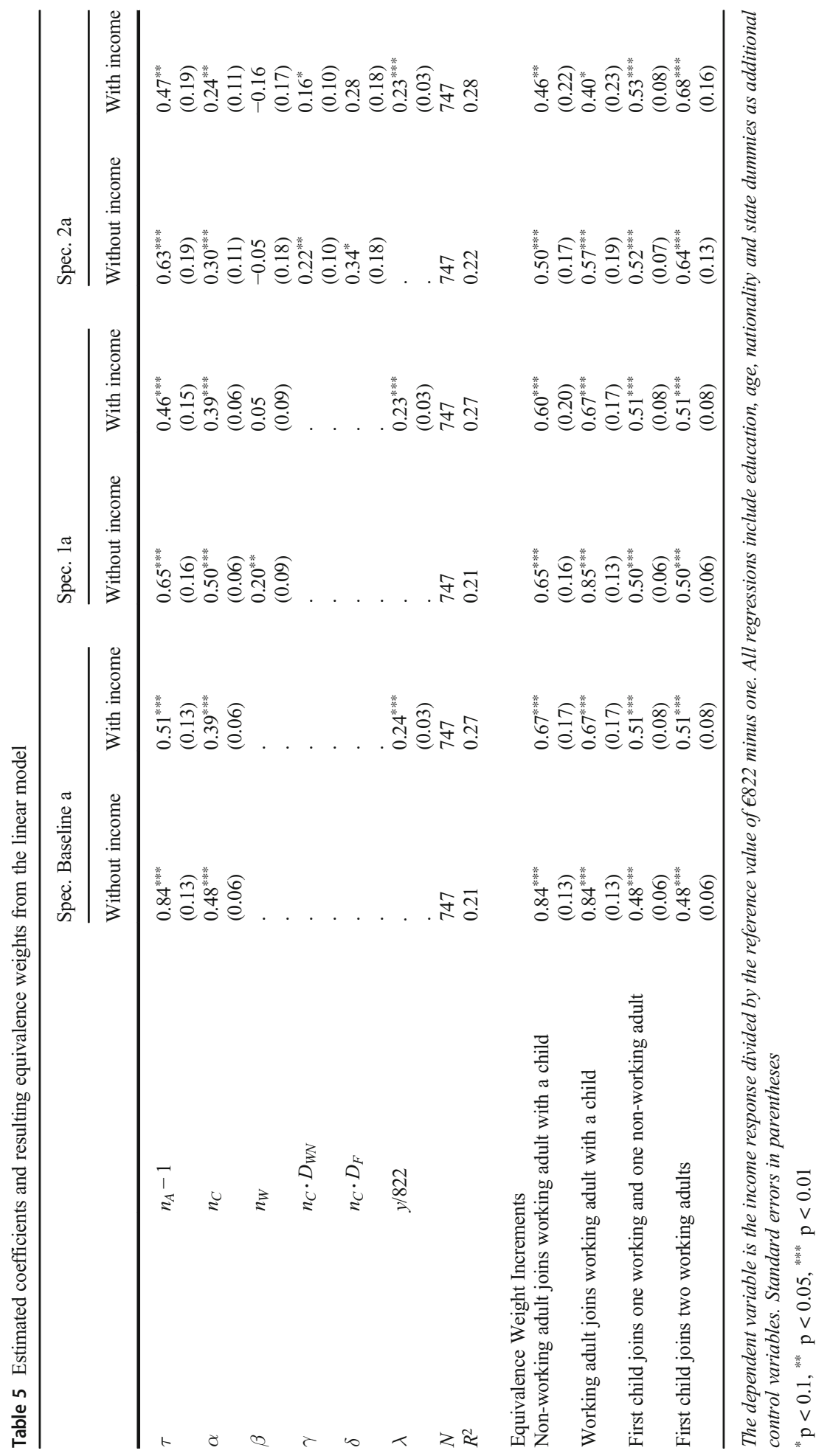


Other explanations are also conceivable, though. On the one hand, KSS' massive compensations for singles' labor market work could be the outcome of a focusing illusion induced by their survey design. On the other hand, our research design may necessitate a cautious interpretation of our results when making inferences about childless adults. One must keep in mind that our sample exclusively consists of households with children. As long as all respondents base their own income response on the same welfare evaluation, we are able to identify an adult's equivalence weight by having our income evaluation question refer to an out-of-sample household with no children. We thus have to assume this condition to hold. We also do not observe pure changes in the number of working adults as these always occur in the presence of children. This may explain why the material cost of labor in specification 2 becomes manifest in time restrictions with respect to childcare only.

\subsubsection{Linear model}

To ensure that our results are robust to the choice of the equivalence scale specification, we now examine the outcomes of estimating a fixed-increment equivalence scale within a linear model. As in the previous subsection, we first ignore and then consider own-income effects in the three analogous specifications (Baseline a, Specification 1a and 2a). Table 5 reports the related results.

The great advantage of the linear regression is that one can straightforwardly use its estimates to determine individuals' equivalence weight increments. The linear model replicates our main results. All the equivalence weight increments reported in the bottom panel of Table 5 are marginally below their counterparts in the nonlinear analysis. The slight downward adjustment may originate from the fact that the linear model cannot accommodate economies of scale in the number of children while it does identify scale economies in the number of adults separately as opposed to the nonlinear model that captures economies of scale in adult equivalents including children. In the presence of scale economies, averaging the equivalence scale increments of children in one constant parameter will lead to lower weight increments for the first child. The second adult's equivalence weight increment will be lower than in the nonlinear model, if the scale parameter $\theta$ averaged greater economies of scale (expressed by a lower equivalence elasticity) for adults and lower economies of scale (expressed by a higher equivalence elasticity) in the number of children.

\section{Conclusion}

In this study, we have proposed a refinement of a survey instrument developed by Koulovatianos et al. (2009) to estimate the subjectively perceived cost of children in differently time-constrained households. An analysis of responses collected from mothers in Germany has shown that children impose substantial monetary costs onto their households and that these tend to increase with parental nonmarket time restrictions. Furthermore, while we have not found evidence that switching from not working to working fulltime generates material cost for childless households, we have discovered that the respective cost is sizable for families with children. This might indicate that the perceived material cost of labor arises primarily from restrictions in the time available for household production, e.g. childcare.

These findings may have important consequences for the analysis of households' material well-being and inequality. For instance, our estimates of the linear specification 2a with 
income effects suggest that for two childless working adults to experience the same material well-being as a single non-working adult receiving $€ 822$, a total monthly income of only $€ 978$ is necessary. For two working adults with one (two) child(ren), a total monthly income of $€ 1529$ ( $€ 2080)$ is required. The corresponding values implied by the frequently used modified OECD scale are $€ 1233$ and $€ 1480$ ( $€ 1726$ ), respectively. Hence, our results suggest that adjusting income using the OECD scale underestimates the material well-being of timeconstrained childless couples and overestimates the material well-being of households with children, relative to the reference household. Our findings imply that relative equivalized incomes of families with children are lower, and their poverty rates higher, than those determined using the OECD scale. This holds in particular for time-restricted households with multiple children, for whom the OECD scale overstates material well-being also in relation to families with no time restrictions. If there is a positive link between income, time restrictions and the number of children, using the OECD scale instead of our estimates will result in an overestimation of the degree of income inequality within the group of families with children. In more aggregate analyses, estimated inequality may deviate into either direction, depending on how the share of childless households varies across the income distribution. In either case, the correct assessment of inequality calls for accurate estimates of children's and other household members' income requirements.

Our findings emphasize the need to collect reliable and suitable data for estimating the cost of children. In general, when one wants to use subjective evaluation data to estimate the value of some good or economic circumstance, it seems advisable to survey groups that have experience with it. Comparing our results to Koulovatianos et al. (2009), however, we see that deviations from this rule might not always be problematic. The estimated cost of children turns out to be quite similar across both studies. Hence, the fact that the majority of respondents in the KSS study did not have children does not seem to matter much. Instead, it looks like respondents with and without children have a similar understanding of what a child needs. We do find, however, that compensations asked in return for adults' labor supply strongly depend on the presence and number of children. This may be due to four different reasons. First, our survey focusses on income compensations to keep the material standard of living constant, whereas the study of KSS asks more generally about the standard of living. If the latter includes benefits from leisure, the difference in the compensations asked in return for labor market work of childless adults may reflect the monetary equivalent of the value of forgone leisure. Secondly, there may be systematic differences in income responses resulting from slight adjustments in the underlying survey design. Our design reduces the threat of a focusing illusion that may cause an overestimation of the subjective cost of time spent working. It is also possible that gender differences or other aspects by which the two samples differ, e.g. the large share of students in the KSS study, are responsible for the difference. Lastly, the fact that we do not observe childless adults may affect the quality of our estimate of the cost of childless adults' full-time employment. Any one or a combination of these factors could cause the substantially lower compensations that we find for childless adults and households with just one child. It seems to be worthwhile for future research to assess the determinants of subjective evaluations of the disutility and material cost of labor in more detail.

We have addressed some limitations of our approach. One issue is the so-called preference drift. Correcting for this effect, we found somewhat greater income requirements for children. Other limitations cannot be circumvented that easily. We mentioned that problems related to sample selection as well as untestable differences in the definition of material living standards might pose such challenges. Similarly, systematically different evaluations of the reference 
household's standard of living could affect our results in a way that we cannot control. A solution to this problem would be to have respondents compare their current household situation solely to arrangements that they experienced in the past. This would require data from respondents who recently experienced changes in the number of children or their household's time-restrictedness. These respondents could then be asked to compare their current household needs to those they had before the change in their household type. To the best of our knowledge, such data is not yet available. General adjustments in the reference household definition, such that respondents' actual household characteristics do not differ too much from those of the reference household, may constitute a simpler, albeit less precise approach to solving the same problem. Surveys focusing on couples with different numbers of children, for instance, could have them refer to family arrangements that they are likely to have experienced in the past, e.g. childless couples. These two latter suggestions also provide room for further research.

Supplementary Information The online version contains supplementary material available at (https://doi. org/10.1007/s10888-020-09467-2).

Funding Open access funding provided by Projekt DEAL.

\section{Compliance with ethical standards}

Conflict of interest The authors declare that they have no conflict of interest.

Open Access This article is licensed under a Creative Commons Attribution 4.0 International License, which permits use, sharing, adaptation, distribution and reproduction in any medium or format, as long as you give appropriate credit to the original author(s) and the source, provide a link to the Creative Commons licence, and indicate if changes were made. The images or other third party material in this article are included in the article's Creative Commons licence, unless indicated otherwise in a credit line to the material. If material is not included in the article's Creative Commons licence and your intended use is not permitted by statutory regulation or exceeds the permitted use, you will need to obtain permission directly from the copyright holder. To view a copy of this licence, visit http://creativecommons.org/licenses/by/4.0/.

\section{References}

Apps, P., Rees, R.: Household production, full consumption and the costs of children. Labour Econ. 8(6), 621648 (2001)

Bertrand, M., Mullainathan, S.: Do people mean what they say? Implications for subjective survey data. American Economic Review. 91(2), 67-72 (2001)

Biewen, M., Juhasz, A.: Direct estimation of equivalence scales and more evidence on Independence of base. Oxf. Bull. Econ. Stat. 79(5), 875-905 (2017)

Bittman, M., Goodin, R.E.: An equivalence scale for time. Soc. Indic. Res. 52(3), 291-311 (2000)

Bollinger, C., Nicoletti, C. and Pudney, S.: Two Can Live as Cheaply as One... But Three's a Crowd. Discussion Papers in Economics, No. 12/23, The University of York (2012)

Bradbury, B.: Family size equivalence scales and survey evaluations of income and well-being. Journal of Social Policy. 18, 383-408 (1989)

Bradbury, B.: Time and the cost of children. Rev. Income Wealth. 54(3), 305-323 (2008)

Bundesagentur für Arbeit: Analyse der Grundsicherung für Arbeitsuchende. Juli 2013. Nürnberg: Bundesagentur für Arbeit (2013)

Coulter, F.A., Cowell, F.A., Jenkins, S.P.: Differences in needs and assessment of income distributions. Bulletin of Economic Research. 44(2), 77-124 (1992) 
Cutler, D.M., Katz, L.F.: Rising inequality? Changes in the distribution of income and consumption in the 1980 s. Am. Econ. Rev. 82, 546-551 (1992)

Ekert-Jaffé, O., Grossbard, S.: Time cost of children as parents' foregone leisure. Math. Popul. Stud. 22(2), 80$100(2015)$

Folbre, N., Murray-Close, M., and Suh, J.: Equivalence scales for extended income in the US. Review of Economics of the Household, 1-39 (2017)

Frey, B.S., Stutzer, A.: What can economists learn from happiness research? J. Econ. Lit. 40(2), $402-435$ (2002)

Gardes, F., Starzec, C.: A restatement of equivalence scales using time and monetary expenditures combined with individual prices. Rev. Income Wealth. 64(4), 961-979 (2018)

Garner, T.I., de Vos, K.: Income sufficiency v. poverty Results from the United States and The Netherlands. Journal of Population Economics. 8(2), 117-134 (1995)

Goedhart, T., Halberstadt, V., Kapteyn, A., and Van Praag, B.: The poverty line: concept and measurement. Journal of Human Resources, 503-520 (1977)

Gustafsson, B., Kjulin, U.: Time use in child care and housework and the total cost of children. J. Popul. Econ. 7(3), 287-306 (1994)

Kahneman, D., Krueger, A.B., Schkade, D., Schwarz, N., Stone, A.A.: Would you be happier if you were richer? A focusing illusion. Science. 312(5782), 1908-1910 (2006)

Kapteyn, A., Van Praag, B.: A new approach to the construction of family equivalence scales. Eur. Econ. Rev. 7(4), 313-335 (1976)

Koulovatianos, C., Schröder, C., Schmidt, U.: On the income dependence of equivalence scales. J. Public Econ. 89(5), 967-996 (2005)

Koulovatianos, C., Schröder, C., Schmidt, U.: Nonmarket household time and the cost of children. J. Bus. Econ. Stat. 27(1), 42-51 (2009)

Nelson, J.A.: Household equivalence scales: theory versus policy? J. Labor Econ. 11(3), 471-493 (1993)

OECD: What are equivalence scales?, available at http://www.oecd.org/eco/growth/OECD-NoteEquivalenceScales.pdf (2005)

Pahl, J.: Family finances, individualisation, spending patterns and access to credit. Journal of Socio-Economics. 37(2), 577-591 (2008)

Pollak, R.A., Wales, T.J.: Welfare comparisons and equivalence scales. Am. Econ. Rev. 69(2), 216-221 (1979)

Rojas, M.: A subjective well-being equivalence scale for Mexico: estimation and poverty and income-distribution implications. Oxf. Dev. Stud. 35(3), 273-293 (2007)

Schwarze, J.: Using panel data on income satisfaction to estimate equivalence scale elasticity. Rev. Income Wealth. 49(3), 359-372 (2003)

Van den Bosch, K., Callan, T., Estivill, J., Hausman, P., Jeandidier, B., Muffels, R., Yfantopoulos, J.: A comparison of poverty in seven European countries and regions using subjective and relative measures. J. Popul. Econ. 6(3), 235-259 (1993)

Van Praag, B.: The welfare function of income in Belgium: an empirical investigation. Eur. Econ. Rev. 2(3), 337-369 (1971)

Van Praag, B.M.S., Ferrer-i-Carbonell, A.: Happiness Quantified: a Satisfaction Calculus Approach. Oxford University Press, Oxford (2004)

Van Praag, B., Van der Sar, N.L.: Household cost functions and equivalence scales. J. Hum. Resour. 23(2), 193210 (1988)

Van Praag, B.M., Warnaar, M.F.: The cost of children and the use of demographic variables in consumer demand. Handb. Popul. Fam. Econ. 1, 241-273 (1997)

Publisher's Note Springer Nature remains neutral with regard to jurisdictional claims in published maps and institutional affiliations. 